\title{
Redistribution and Economic Decline
}

\author{
Sven R Larson \\ PhD, Hill City Skunkworks, LLC, USA \\ sven.larson@protonmail.com
}

\begin{abstract}
Economic activity is kept stable by means of explicit and implicit contracts. These contracts, in turn, carry the confidence of economic decision makers as far into the future as the free market will trust them. A change in the trust of an implicit contract leads to a decline in economic activity; if that decline, while unexpected, is manageable, the resulting macroeconomic downturn will be a recession. If, on the other hand, the negative changes are beyond what the present system of explicit and implicit contracts can manage, the recession can escalate into a depression. The line between a recession and a depression is more easily crossed when government fails as an above-market carrier of confidence.

KEY WORDS: decision makers, free market, recession, depression.
\end{abstract}

This paper is an abbreviated version of: Austerity and Stagnation, Part 1: A NonWalrasian Approach to Economic Stability, Available at SSRN: https://papers.ssrn. com/sol3/papers.cfm?abstract_id=3037141

\section{Introduction}

Confidence is the fabric that keeps an economy stable. It manifests itself in economic decisions as reference points for confidence; more specifically, explicit and implicit contracts between economic agents, determining prices, product quality and frequency of trade. 
Explicit contracts are written, legally enforceable agreements that regulate the obligations and entitlements of the parties involved. Implicit contracts are less stringent in their definition, but consist primarily of information, identifiable habits and values facilitating the successful forecast of potential gains of trade. A price sticker in a supermarket is an example: knowing that the price of a gallon of milk, a loaf of bread or a pound of pork chop will remain approximately the same from one day to the next, consumers make it a habit of shopping there.

Despite the lower level of clarity in the definition of an implicit contract, this type of contract is essential to the stability and continuity of our economy. Implicit or semi-implicit contracts are responsible for the predictable continuation of approximately 90 percent of private consumption in the United States. Implicit contracts apply to regularly purchased items, such as non-durable goods, housing, utilities and retail services.

Semi-implicit contracts are contracts where prices are either discretionally negotiated or change between occasions of consumption but remain generally within a predictable framework. Semi-implicit contracts apply to products typically purchased with lower frequency: health care, transportation services, food services and accommodations, some financial services, and education.

The categorization of consumption based on the implicit-contract definition is approximate, but it suggests how important implicit contracts are in an industrialized economy. Consumer spending under such contracts is responsible for close to two-thirds of U.S. GDP (65 percent in 2016).

The predictability of implicit contracts depends on the willingness of both parties buyers and sellers - to continue gainful trade under present circumstances. Together, they build confidence in their ability to reap gains from trade in the future, based on a pattern of explicit or implicit contracts.

When there is a change to the conditions that permit continuation of an implicit contract, the adjustment that follows will take place on free-market terms. Since the free market is, essentially, a complex trial-and-error system, adjustment processes during which predictability of business is limited - will commonly be temporary in nature. This is the case both at the microeconomic level, affecting individual products and markets, and at the macroeconomic level, causing recessions and growth periods in the business cycle.

Alas, in an economy with a minimal government, the free market is fully responsible for determining the length and monetary value of implicit contracts, as well as for correcting those contracts when needed. When government engages in economic 
redistribution, it provides vehicles for above-market confidence, in the form of explicit or implicit contracts between government and the private sector. These contracts form a framework of stability within which private citizens can engage in gainful trade. Since government provision and production is based in taxation and legislation, its implicit contracts are rightfully perceived as superior to the confidence that can be built up and maintained by the free market. Put plainly, government is taken for granted. Due to its superior position as a confidence provider, government can do exceptional harm to the economy by mismanaging that role. Under mismanagement, government's contributions to stability and predictability become conveyors of instability and uncertainty.

\section{Uncertainty, Confidence and Fiscal Policy}

The purpose with implicit contracts is to carry confidence and value through time. If implicit contracts are extended through multiple periods of time, allowing decision makers to plan their economic activities through time, then the decision maker's confidence will extend through time as well.

However, it would be wrong to assume that implicit contracts, materialized as, primarily, price stickers, will extend linearly through time. Confidence is built by means of increased use of price stickers, but while the price sticker can technically be extended infinitely, the free market will set a finite maximum for the extension of contracts and confidence. The price sticker, the money that denominates the price sticker and the liquidity that enables the carrying of value through time, all exist within a reality that, by default, is fundamentally uncertain. Decision makers are able to make uncertainty manageable with the use of price stickers, but they do not eliminate uncertainty as such.

Since uncertainty does not go away, but is manageable, the manageability is dependent on how reliable the decision maker considers his reference points to be in the future. Thanks to a fixed wage, a worker may be able to accurately predict his pay over the next three, six or twelve months, deriving great confidence in the future from the price sticker on his labor. But would he, with the same level of confidence, assume that his wage is going to be the same two, five or ten years hence? The price stickers on groceries at the local supermarket inspire confidence in the consumer, motivating him to predict his costs for food over the next year; at the same time, it would be prudent of him not to predict the cost of the same items two, five or ten years hence. The possibilities of changing circumstances are simply too many. Schematically: 
Figure 1

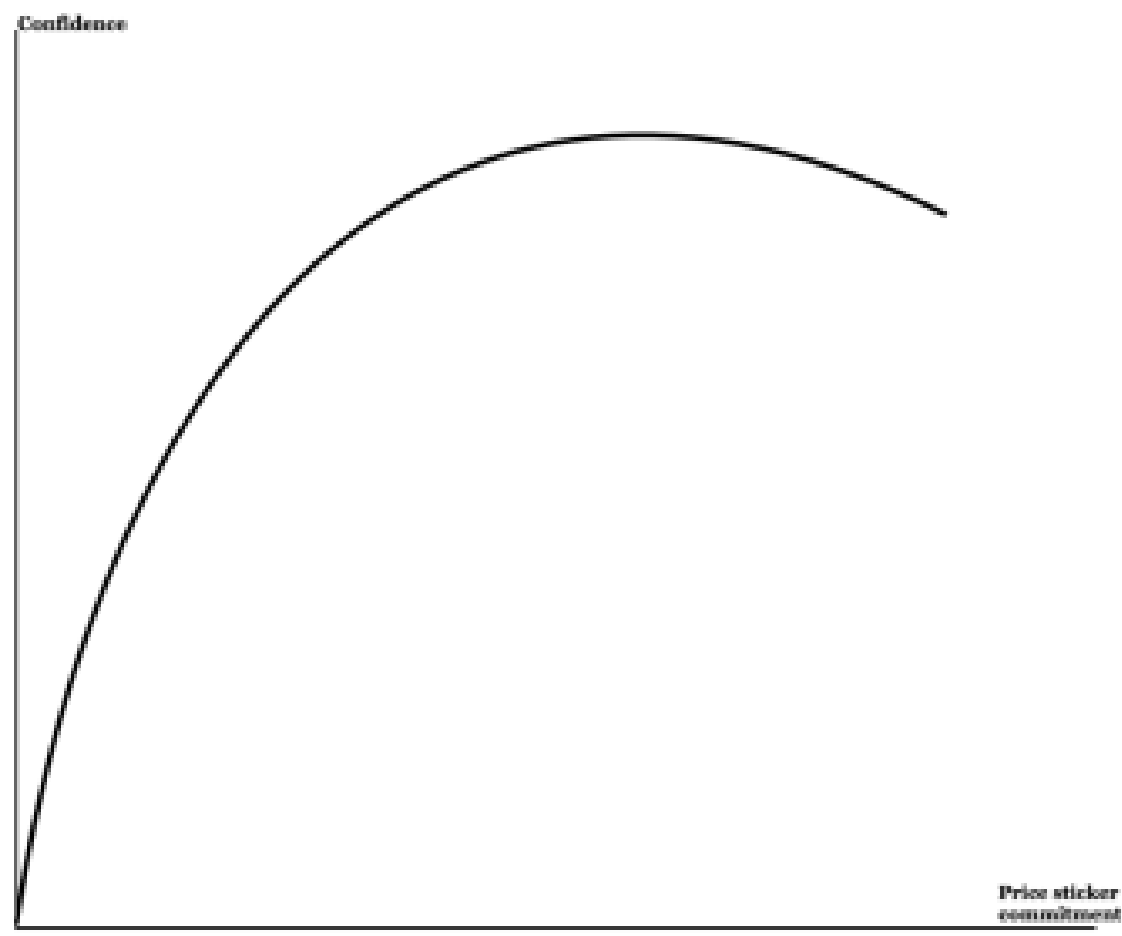

Figure 1 should not be construed as a mathematical function. It is used solely for illustrative purposes, as a depiction of a causal relationship. It is not the case that decision makers strive to maximize confidence, as one could be led to believe from the shape of the curve. The downturn of the curve is not included to suggest a maximization behavior, but to point out that price stickers, and therefore the decision maker's confidence, cannot stretch infinitely into the future. Uncertainty, still present outside of the decision maker's path of confidence through time, eventually overwhelms any attempt at making the future as predictable as possible.

What is technically depicted as a maximum point, is in reality the state of mind of economic decision makers where "things are as good as they can be".

Of relevance to the understanding of how confidence is built is the early segment of the curve in Figure 1. Confidence is not built linearly: the decision maker's need for price stickers is highest when his confidence is at its lowest. At the origin in Figure 1, confidence is at zero and the decision maker lives in fundamental uncertainty. 
To quip, one reference point to hang confidence on is infinitely better than zero; two is twice as good as one.

Confidence is carried into the future on prices stickers by means of money, the universal denominator of value. The fewer price stickers a decision maker has access to, the more of his value he keeps liquid. Flexible prices never allow the decision maker to determine, beforehand, how much cash he needs to bring to the market; price stickers allow him to set aside portions of his liquidity for future spending. Furthermore, for every price sticker he can use, the decision maker grows more confident in his pursuit of other price stickers, and is thereby ready to commit more of his value to future spending. If the decision maker can predict, with a reasonable level of confidence, his wage thanks to a wage contract; the cost of groceries thanks to price stickers in the supermarket and other regular costs of living; then he is more inclined to agree to the monthly cost of a multi-year car loan or mortgage, than if none of the basic items in his budget were foreseeable from one period of time to another.

As the decision maker expands the use of price stickers, he has less need for liquidity as a precaution against economic contingencies. His commitment to price stickers constitutes a transition away from liquidity.

It also constitutes a transition from casual, occasional interaction on markets to long-term, stable flows of economic activity. All other things equal, high levels of confidence are associated with high levels of consumer spending; high levels of value commitment by consumers, through price stickers, lead to reciprocal commitments from employers. They make long-term commitments to production resources, leading to both investments and labor hiring.

In other words, price stickers are the fabric from which confidence and, gradually, macroeconomic activity are built. Contrary to the Walrasian theory where flexible prices lead to higher use of economic resources, the Shackle-Alchian theory suggests the exact opposite: price stickers, not flexible prices, benefit high employment of economic resources.

By allowing economic decision makers to commit increasing shares of their value, price stickers provide the vehicle for macroeconomic expansion. They carry multiplied economic activity forward in time. In this capacity, price stickers successfully serve the growth in economic activity, up to the point where "things are as good as they can get". This is the growth period of the business cycle.

Theoretically, confidence and the successful commitment of value with price-sticker support can remain at the good-as-it-gets stage forever. In practice, every growth period ends when a sufficient number of decision makers find good reasons to weaken 
their confidence in the future. In a reality that is fundamentally uncertain, the reach through time of the fabric that provides for confidence is always limited.

The weakening of confidence is not necessarily as smooth and gradual as its construction. Since reality is fundamentally uncertain, decision makers have a natural inclination to be cautious. In the choice between committing a portion of his value to future spending subject to price stickers, and retaining the same portion of his value as liquidity, he will by default prefer the latter unless he has explicit reason to believe that he can rely on the price stickers offered as reference points into the future. Therefore, in the origin of uncertainty (see Figure 1) a decision maker needs no new information to remain in fundamental uncertainty. By contrast, he needs regular reaffirmation in the price stickers he relies on, in order to continue to trust them as reference points for his confidence.

Because of this asymmetry between confidence and uncertainty, a decline in economic activity can be significantly more rapid than a growth period. A decline begins when decision makers have weaker reasons than before, or no reasons at all, to believe in their price stickers. As confidence weakens, decision makers move to increase the liquidity in their value, primarily by reorganizing their spending that is subject to implicit-contract price stickers.

Confidence contracts faster per period of time than it expands. It is also worth considering the consequences of "disappointment": when decision makers have built their confidence on a pattern of price stickers, and those stickers turn out to be unreliable, or at least unhelpful in supporting their confidence, decision makers will be more cautious the next time they expand their confidence. They apply a higher threshold of reassurance before re-establishing their confidence; it is possible to explain the persistence of some economic recessions based on this confidence asymmetry.

\subsection{Confidence leadership and the business cycle}

The purpose of the price sticker is to construct a reference point for confidence in time and space. Confidence, in turn, is essential to the economic decision maker for the realization of gains from trade, or, in Alchian's (1950) terms, the pursuit of positive profits. However, there are limitations to the ability of reference points to carry confidence. Markets and individuals are never isolated from the rest of the economy. If price stickers were created on just one market in the economy, the presence of uncertainty in the rest of reality would overwhelm the limited body 
of confidence that those price stickers could produce. They would, effectively, lose their economic meaning.

Conversely, when price stickers proliferate throughout the economy they have a multiplier effect on confidence. This is how confidence is built at the microeconomic level, but it is also the key to its aggregate, macroeconomic effects.

An economic environment filled with price stickers provides a predictable economic environment that new decision makers can accept as a given. That system is a positive externality for individual decision makers, requiring a more limited learning process than if every new consumer, worker or entrepreneur had to start in fundamental uncertainty. Instead, every new decision maker can learn to benefit from the existing system of confidence by means of "imitation" and "trial and error". Calling this"conscious adaptive behavior", Alchian explains imitation (1950, 218):

wherever successful enterprises are observed, the elements common to these observable successes will be associated with success and copied by others in their pursuit of profits or success."Nothing succeeds like success."

Without explicit mention of reference points, Alchian also notes that the role of those points and of the price sticker is elevated to codify and institutionalize economic activity:

What would otherwise appear to be merely customary "orthodox," nonrational rules of behavior turns out to be codified imitations of observed success, e.g., "conventional" markup, price "followship," "orthodox accounting and operating ratios, "proper" advertising policy, etc.

Imitation is prevalent throughout the economy. However, to function properly, imitation requires leadership: some decision makers lead in maintaining stickeredprice relations to others; others follow by imitating the successful behavior of leaders. In doing so they multiply confidence and thereby contribute to the positive externality that becomes the fabric of macroeconomic stability.

A successful system of reference points - price stickers, codification, economic institutions - maintains economic stability so long as it retains the confidence of economic decision makers. In line with the difference between perfect-foresight based Walrasian theory and uncertainty-based original Keynesian theory, the peak of macroeconomic activity under confidence-carried stability is not to be confused 
with full employment in a Walrasian system. Macroeconomic stability fosters gradual expansion of confidence up to the point where "things are as good as they can get". This means either that all available economic resources are employed, or that some resources are still idling involuntarily. The peak point for economic expansion is determined by:
a) the level of confidence that economic decision makers are willing to place in an existing system of reference points; and
b) how far they can improve that system and still reliably strengthen their confidence in positive profit from their economic actions.

Just as success of confidence building spreads through the economy, there is a multiplier effect for the disappointment in reference points. When decision makers find that they have misplaced their trust in their reference points, their reaction is similar in kind to, but faster in pace than, their reactions when they successfully build up their confidence. The pace of change in confidence and uncertainty is in large part decided by the behavior of price leaders, or, as they are more appropriately referred to, confidence leaders. They advance to the forefront of confidence building by virtue of their reputation and proven success; confidence leaders can be expected to be more skilled than average economic decision makers at managing changes in circumstances.

So long as confidence leaders serve their purpose, economic stability prevails. The stability extends to regular recessions, accounted for and manageable by experienced decision makers. When, on the other hand, confidence leaders are faced with challenges that are sufficiently unfamiliar, their skills and experience no longer apply. At this point they have to resort to a more basic process for managing uncertainty, or "trial and error" (Alchian 1950, 219). An economic downturn that is sufficiently unfamiliar to confidence leaders, and which therefore deprives their followers of reliable reference points in their decision making, deprives all participants in the economic system of stability and predictability.

In absence of stability and predictability, a recession becomes a gateway to a depression. Under original Keynesian theory, the depression inherent to the economic system - it is no anomaly the cause of which requires special explanations. It is inherent because its root cause is the failure of the confidence-building decision process.

Here, Walrasian economic theory stands in stark contrast to original Keynesianism. Walrasian theory cannot incorporate depressions; even recessions are anomalous to its axiomatic foundation. When every decision maker is guided by perfect foresight, every 
expectable change in economic activity is immediately accounted for. Furthermore, the perfect-foresight axiom reduces the confidence leader to a contradiction in terms. There is no need for imitation or other reliance on others for explicit or implicit decision guidance.

The combination of uncertainty and the free market renders systemic solidity to original Keynesian economic theory. The free market separates successful confidence leaders and their followers from those who fail; failed decision makers perish, and their demise allow prevailing leaders and followers to adapt and improve their decisionmaking process.

Herein lies the source of economic stability that carries the economy through growth periods and recessions. As mentioned, it also explains a depression as a phenomenon inherent to the economic system. The cause of a depression is no longer exogenous; its rationalization no longer requires dedicated theory, but is always one of the possible outcomes of economic decision making.

\section{Recessions, Depressions and Government}

So long as successful confidence leaders retain the trust of their followers, the collective outcome of a negative change to economic circumstances will be mitigated. An economic downturn results in a recession, but no more than that. However, if confidence leaders fail at adapting to changing circumstances, their failure will amplify the economic downturn.

The line between mitigation and amplification begins in the aforementioned quote from Keynes. The decision "not to have dinner today" is made in response to a change in circumstances significant enough to alter the decision maker's spending habits. The decision disrupts economic relations established under the current system of price stickers: to stay within Keynes's example, the restaurant continues to offer its menu with fixed prices for its dinner choices, expecting in return a continuous flow of dinner guests. When some of them make the decision to cancel their eating-out plans, causing a decline in dinner sales, one side of the implicit contract between buyer and seller is broken.

It is perhaps irrelevant to talk about confidence leaders in the restaurant dinner market. Consumer markets generally do not rely on identifiable decision makers that consumers normally would trust. It is more appropriate to involve identifiable confidence leaders on the entrepreneurial side of the economy. Consumers rely instead 
on general information, conveyed through public sources, reporting overall economic trends and other information affecting the general confidence and mood of consumers. If, for example, it is reported that consumers in general have reduced spending recently, and that consumer confidence in general is in decline, individual consumers may rethink their own future plans and adopt a less confident outlook on the future. In Keynes's case, this leads to a general decline in spending on restaurant dinners; the decline is of a nature that it does not in itself promise any return to previous levels of spending at eating establishments.

Restaurateurs, initially holding out and hoping for indications of a rebound in spending, eventually respond by reducing the cost of their operations. Applied generally, this is the sequence of a recession underway.

It is not the first response by entrepreneurs to drop the price. His first response is to try to hold out and bridge over the gap that is the initial decline in revenue. This response is consistent with original Keynesianism, but antithetical to perfect-foresight Walrasian theory. There, the immediate response to the decline in demand would be an immediate drop in the dinner price.

Walrasian theory can deviate from its flexible-price response if and only if it is amended by a theory dedicated to the explanation of sticky prices. For example, menu-cost price theory suggests a delay in price cuts due to the costs of remaking price stickers (in this case, literally the menu). The menu cost is an imperfection in an otherwise perfect economic system, begging the question why perfectly rational economic decision makers have not been able to overcome the menu cost and remove this marginal imperfection from their system.

Under original Keynesian theory the restaurant maintains its menu for entirely different reasons. The menu is a promise to restaurant patrons, a promise that both parties benefit from. In return for the promise, the restaurant is rewarded with a steady flow of dinner guests. This flow makes business operations predictable and promises positive profits; decision makers can concentrate on other agreements - explicit as well as implicit - between the business on the one hand and suppliers and workers on the other.

With the restaurant menu prices as a metaphor for price stickers in general, their purpose is to provide customers with an implicit contract for their continued patronage. It is worth some decline in sales not to break that contract. So long as the decline in business is predictable, or unsurprising, the decline is tantamount to a recession at the macroeconomic level; when, on the other hand, the drop in sales at the individual 
business is surprising, or unpredictable, the drop in economic activity may escalate into a depression.

The difference between a recession and a depression is determined by the interaction between confidence leaders and followers. If confidence leaders maintain the trust of followers, then even under unforeseen circumstances the overall system of price stickers will prevail and secure a mitigated macroeconomic response to the initial decline in spending. The macroeconomic reaction is still a recession. If, however, confidence leadership is disrupted, the initial decline in economic activity is amplified as economic decision makers struggle to re-establish reference points for their confidence. In this case the macroeconomic decline escalates into a depression.

Under unforeseen circumstances, the difference between a recession and a depression is determined by the point where past experience no longer applies. Even in the face of unforeseen events, past experience can prove a reliable guide back to stability and predictability. However, as Davidson explains $(1978,16)$, when past experience cannot be used as a base for probability judgments about the future,

Uncertainty becomes of utmost importance and those actions which are the least costly to reverse may often become the most preferred as the degree of uncertainty increases. In a world of uncertainty, he who hesitates is saved to make a decision another day.

This rational self-interest is essential. It saves the price leader but weakens or eliminates the positive externality that the leadership produces. The point where rational selfinterest conflicts with the externality effect of leadership is the point where the positive effect of price leadership caps out.

\subsection{Government and above-market confidence}

In a free-market system with minimal government as defined by Nozick (1974), only individual decision makers will be producers of confidence externalities. Government participates in the economy only as the guarantor of life, liberty and property, and as the impartial arbiter of legal disputes, thus only providing an institutional base for the very existence of an economy.

In an economy with a minimal government, the free market puts a cap on the confidence of economic decision makers. The market becomes the final arbiter of when confidence spills over in irrational exuberance. This system of market-determined confidence leadership is disrupted when government expands its participation in the economy 
beyond its minimal boundaries. By engaging in activities that affect the financial conditions of individual economic decision makers, government affects confidence leadership by providing positive confidence externalities.

Because of its unique legal status, government is immune to Davidson's rationality. In addition to private-market borrowing, government has two unique funding mechanisms - taxation and deficit monetization - that elevate it above the free market's confidence cap, and therefore above the restrictions on its activities that uncertainty places on private economic decision makers.

Its participation expands by means of income redistribution:

- a select group of citizens, defined as eligible, receive a benefit that is defined in quality, quantity and economic value;

- another select group of citizens, different than the eligible group, pay the taxes that fund the benefit.

The eligible group receive a benefit that provides confidence in the same way as price stickers do, but with the back-up of government funding. Correspondingly, taxpayers, while seeing their disposable income decline, also have a price-stickered confidence reference point with a longer life than privately created stickers.

A system of entitlement benefit programs and taxes to fund them is also known as the welfare state. Due to the removal of Davidson's rationality, the welfare state's price stickers are more reliable than comparable, privately provided stickers. They therefore create stronger positive externalities of confidence and move the point where "things are as good as they can get" farther into the future.

The notion of government as an above-market confidence carrier is not isolated to pure economic theory. It has been presented as a motive for the construction of the modern welfare state. Myrdal (1960) and Galbraith (1967) conclude that an elaborate welfare state has long-term positive effects on macroeconomic growth and stability. From a mid-to-late 20th century perspective, it appeared as though their conclusions were the enduring wisdom regarding the macroeconomic role of the welfare state. An elaborate system of programs for economic redistribution would enhance confidence and thereby permanently elevate macroeconomic activity. The theory developed above helps explain their conclusions.

Consistent with original Keynesian theory, the confidence carrying function of government is a two-way street. Since approximately the late 1970s many welfare 
states in Europe have experienced a slowdown in economic growth. Larson (2014) suggests that this slowdown happens when the welfare state reaches a critical mass in terms of share of GDP, that the slowdown appears to be permanent and that it is intimately linked to persistent deficits in government budgets.

Without arguing for or against Larson's proposed evidence, it is worth exploring what happens to macroeconomic stability if there is a causal relationship from the size of the welfare state to a permanent slowdown in growth and therefore in tax revenue. Under the - again uncontested - assumption that welfare state growth eventually causes a slowdown in tax revenue growth; and that, at given spending rates, persistent deficits emerge and lead to the erosion of government credit; a negative fiscal policy reaction in the form of austerity presents a challenge to the welfare state as an abovemarket confidence carrier.

In fact, when viewed in the context of original Keynesian theory, austerity becomes a powerful driver of rapid decline in economic activity. Protracted episodes of austerity can explain both the initial decline and sustained depression of production, consumption and investments in economies such as the Greek during and after the Great Recession.

Specifically, austerity affects the confidence of economic decision makers in either of two ways:

a) Reduced content, qualitatively and quantitatively, of the benefits that the entitled population has been promised; or

b) Higher price of the benefits in the form of increased taxation.

The content reduction - a spending cut - affects the entitled population in many different forms. Each entitlement program plants a reference point in a decision maker's finances. A family that enjoys government-provided daycare for their children count on the quality and quantity of that daycare to remain largely intact over the foreseeable future. Their confidence in the government program allows them to commit their workforce to employers. A spending cut shortens the time that daycare is offered, forcing one or both parents to reduce their workforce commitment. This imposes a cost on the family, disrupts some of their value commitments and thus transmits signals of weakened confidence to those with whom the family interact economically on a regular basis.

When austerity is applied generally to government spending, it has a weakening effect on decision-maker confidence across the economy. By disrupting stable 
economic activity, individuals signal weakened confidence, causing others to respond accordingly. To paraphrase the opening paragraph of chapter 16 of Keynes's General Theory (1936):

An act of austerity means - so to speak - a decision not to provide daycare today. But it does not necessitate a decision to provide daycare or to provide for more school funding a week hence or a year hence or to provide any other entitlement benefit at any specific date. Thus it depresses current spending without promising any future act of spending. It is not a substitution of future government spending for present government spending - it is a net diminution of such spending.

The difference between an individual's decision not to spend money today, and a government's decision, is the difference between an isolated, microeconomic event with some limited impact on the rest of the economy, and a macroeconomic event with immediate repercussions for the economy as a whole. If all consumers decide to reduce spending today, the effect resembles that of government cutting spending, but it does so only in its worst case; a government decision not to spend money today, as promised or as expected by habit, is always of the magnitude that constitutes a worst-case example for private-sector decision makers.

\section{Conclusion}

Economic stability is the product of deliberate actions, taken by economic decision makers who are averse to uncertainty and whose explicit or implicit commitment to future economic activity depends on their state of confidence. By means of freemarket interaction, consumers, entrepreneurs and investors create a system of explicit and implicit contracts that serve as reference points for confidence. The more reliable the reference points are, the more confident economic decision makers are; stronger confidence results in higher levels of economic activity. Government is the only entity that can produce confidence above what the free market can muster. At the same time, government can also tear down confidence more thoroughly than the free market is capable of. The more deeply government is involved in the economy - by means of economic redistribution - the greater are the risks of economic instability when government fails to deliver on its confidence promises. It is a hypothesis of this paper that the original Keynesian theory explained here can significantly enhance an explanation of recent macroeconomic crises, such as in Greece. There is a rich field of research opportunities here, to follow up on this paper. 


\section{References}

Alchian, Armen. 1950. "Uncertainty, Evolution and Economic Theory" Journal of Political Economy 58 (3): 211-221.

Davidson, Paul. 1978. Money and the Real World. London: MacMillan.

Galbraith, John. 1967. The New Industrial State. Princeton: Princeton University Press.

Keynes, John. 1936. The General Theory of Employment, Interest and Money. London: Harcourt.

Larson, Sven. 2002. Uncertainty, Macroeconomic Stability and the Welfare State. Aldershot: Ashgate.

Larson, Sven. 2014. Industrial Poverty: Yesterday Sweden, Today Europe, Tomorrow America. Aldershot: Gower.

Myrdal, Gunnar. 1960. Beyond the Welfare State. London: Duckworth.

Okun, Arthur. 1981. Prices and Quantities. Washington: Brookings.

Shackle, George. 1992. Epistemics and Economics. New Brunswick: Transaction. 